\title{
Post-Seismic Crustal Deformation Associated with the 1995 Hyogo-ken Nanbu Earthquake Derived from GPS Observation - Preliminary Analysis of Trimble Data-
}

\author{
Teruyuki Kato, ${ }^{1, *}$ Yoshiko Kotake, ${ }^{1}$ Shigeru Nakao, ${ }^{1}$ Yasuhiro Hirata, ${ }^{1}$ \\ Toshikazu Chachin, ${ }^{1, a}$ Fumiaki Kimata, ${ }^{2}$ Koshun Yamaoka, ${ }^{2}$ Takashi Okuda, ${ }^{2}$ \\ Hiroyuki Kumagai, ${ }^{2}$ Kazuro Hirahara, ${ }^{3}$ Takehide Nakano,${ }^{3}$ Tsutomu Terashima,, ,b \\ John P. L. Catane, ${ }^{4, c}$ Atsuki Kubo, ${ }^{4, d}$ Takao Tabei, ${ }^{5}$ Tetsuya Iwabuchi, ${ }^{5}$ \\ and Takeshi Matsushima ${ }^{6}$ \\ ${ }^{1}$ Earthquake Research Institute, The University of Tokyo, Bunkyo-ku, Tokyo 113, Japan \\ ${ }^{2}$ Faculty of Science, Nagoya University, Chikusa-ku, Nagoya 464-01, Japan \\ ${ }^{3}$ Disaster Prevention Research Institute, Kyoto University, Uji 611, Japan \\ ${ }^{4}$ Department of Planetary and Earth Science, Faculty of Science, Kobe University, \\ Nada-ku, Kobe 657, Japan \\ ${ }^{5}$ Department of Physics, Faculty of Science, Kochi University, Kochi 780, Japan \\ ${ }^{6}$ Shimabara Earthquake and Volcano Observatory, Faculty of Science, Kyushu University, \\ Shimabara 855 , Japan
}

Within 1 to 4 days following the 1995 Hyogo-ken Nanbu earthquake ( $M 7.2$ ) that occurred on January 17 , 1995, the Japanese University Consortium for GPS Research deployed more than 30 GPS receivers in the hypocentral area to investigate post-seismic activity. Of these stations, we analyzed data from 8 sites that were placed near the hypocentral area; six in Kobe and two in Awaji. Two methods of analysis were employed: 1) change of absolute geocentric coordinates were estimated by assuming Usuda global site, which is about $300 \mathrm{~km}$ northeast of the hypocentral area, as fixed, 2) analyses for short baselines were conducted within the hypocentral area using the automatic processing technique. Results suggest that 1) rapid displacements toward the southeast of more than $4 \mathrm{~cm} /$ year were found at all of the analyzed sites, which might be part of a post-seismic deformation process, 2) largest of which was found at Rokko Farm site, at which displacement amounted to about $3 \mathrm{~cm}$ until the end of February, though its cause were not specified, and 3) local straining seems to be taking place at both Kobe and Awaji areas.

\section{Introduction}

The Hyogo-ken Nanbu earthquake of magnitude 7.2 occurred at dawn on January 17, 1995 and devastated Kobe City and Awaji Island areas, in the western part of Japan (Figs. 1 and 2). The nationwide GPS network that was recently introduced by the Geographical Survey Institute immediately revealed co-seismic deformation in the surrounding area (Hashimoto et al,, 1996). The closest site was, however, about $50 \mathrm{~km}$ away from the epicenter, so that a denser network was necessary to monitor post-seismic deformation in much detail.

Thus, in order to not only monitor post-seismic deformation but also to investigate subsequent activity which might propagate to the surrounding area, the Japanese UNiversity COnsortium for GPS Research (JUNCO) decided to deploy GPS receivers

Received July 14, 1995; Accepted January 5, 1996

* To whom correspondence should be addressed.

a Present address: DX Antenna Co., Ltd., Shinjuku-ku, Tokyo 160, Japan

b Present address: Suma-ku, Kobe 654, Japan

c Present address: 57 San Francisco St., Barrio Kapitolyo, Pasig, Metro Manila, Philippines

${ }^{d}$ Present address: National Institute of Polar Research, Itabashi-ku, Tokyo 173, Japan 
around the hypocentral area and to construct a dense temporal network as soon as possible. Figure 2 shows the distribution of the aftershocks obtained through the automatic processing system at the Abuyama Observatory of the Disaster Prevention

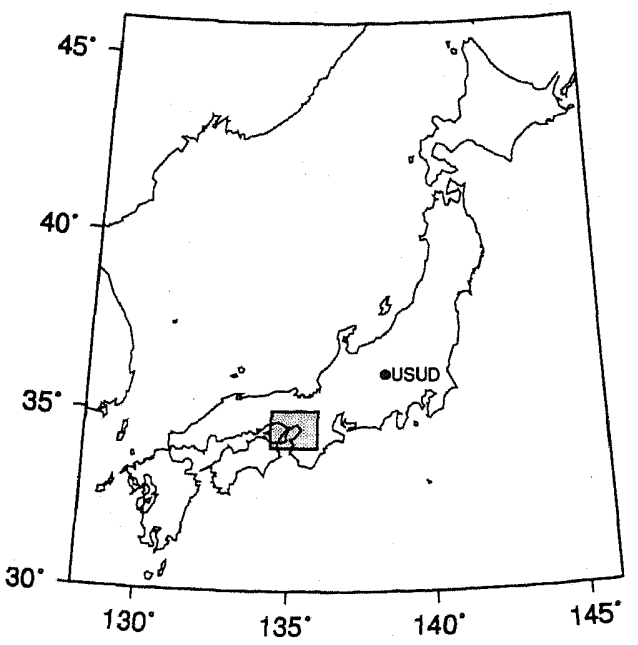

Fig. 1. Map of Japan and the location of Usuda site. The inset box shows the studied area.
Research Institute (DPRI), Kyoto University, based on the data taken from seismic networks by DPRI, the Earthquake Research Institute (ERI), the University of Tokyo, and the Faculty of Science, Nagoya University (Katao, personal communication). It may

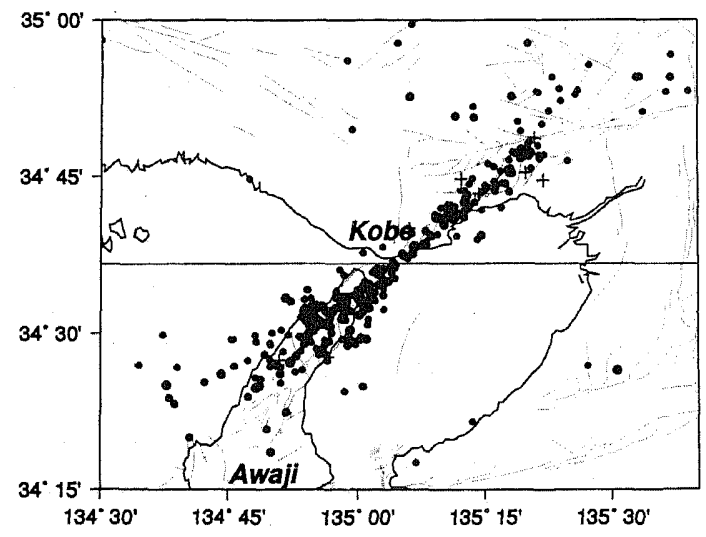

Fig. 2. Aftershock distribution in the area (GROUPHYOGO). MT diagrams in Fig. 4a-f are compiled from data north of $34^{\circ} 37^{\prime} \mathrm{N}$, while those in Fig. $4 \mathrm{~g}$ and $\mathrm{h}$ are compiled from south of $34^{\circ} 37^{\prime} \mathrm{N}$.

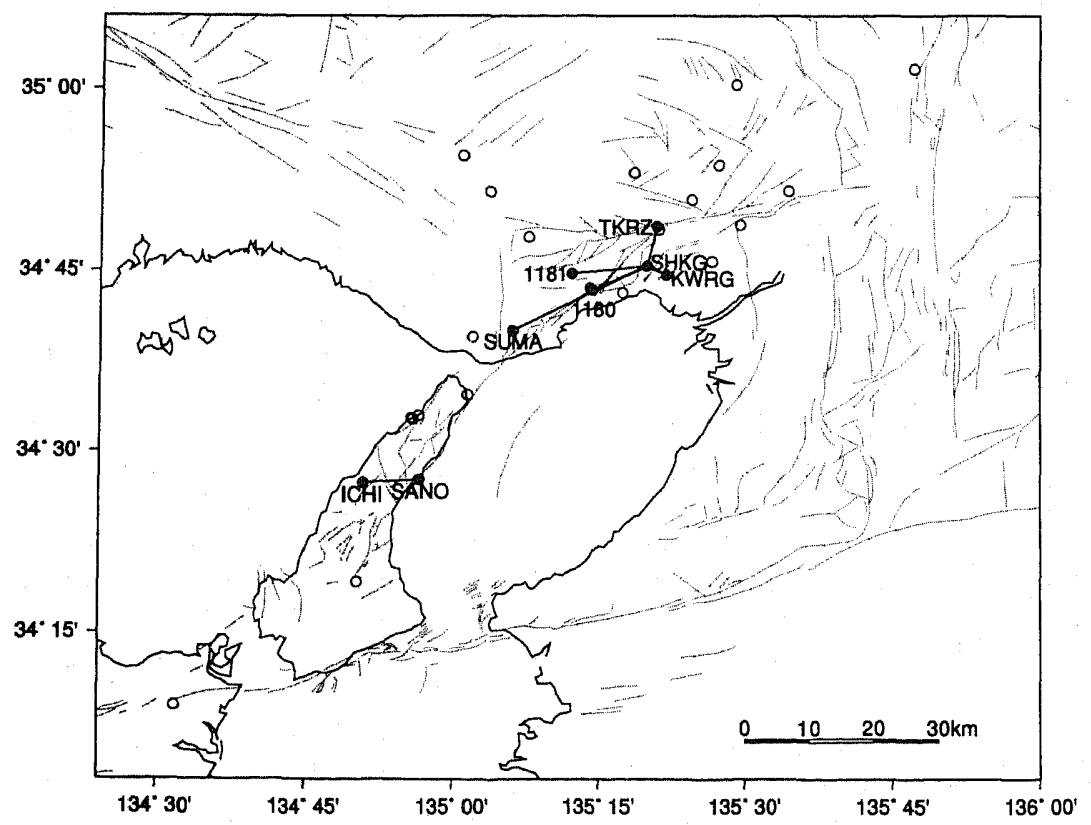

Fig. 3. Urgent GPS network by JUNCO. Sites that was used for analysis are shown by closed circles. Analyzed short baselines are also indicated. Dotted lines denote active faults (Research Group for Active Faults of Japan, 1991). 
be clear that the aftershocks are distributed on the northeast-southwest trending lineament which is nearly on the active fault traces that have been found by Research Group for Active Faults of Japan (1991). GPS receivers were first distributed as close to the area of aftershock activity as possible (Fig. 3). It took 1 to 4 days after the earthquake for the first deployments of more than 15 receivers.

Successive deployments followed until the middle of February and the total number of GPS receivers amounted to more than 30. Two types of GPS dual frequency receivers were used: Ashtech Z-XII (or Topcon GP-R1DY) and Trimble 4000SSE, both of which have capability to acquire full wavelengths of L1 and L2 under Anti-Spoofing circumstances.

During the early part of the field work, data were downloaded to PC at each site. Later, in the middle of February, we implemented a dial-up system using public telephone lines except for four sites where dedicated phone lines were used for realtime kinematic monitorings of the crust (Hirahara et al., 1996). Since these dial-up systems were not compatible between different type of receivers, ERI archived Trimble data, while DPRI downloaded Ashtech data. Archived Trimble data at ERI were converted to RINEX standard format (Gurtner and Mader, 1990) and were sent to DPRI through the Internet. Ashtech data were also converted to RINEX at DPRI and both of the data were stored in the data storage of DPRI.

In this article, we report results obtained through preliminary analysis done by the ERI analysis team using the Trimble data. We used eight sites that were distributed close to the fault (see Figs. 2 and 3). In the analysis, we used two types of procedures: 1) daily geocentric coordinates of all sites were estimated assuming Usuda global site was fixed, and 2) short baselines between sites were estimated every $6 \mathrm{~h}$ to monitor short term deformation of the crust. A brief discussion is included on the postseismic crustal deformation based on the obtained results.

\section{Data and Method}

Figure 3 shows eight selected GPS sites used in this study. Sites were placed on the roofs of local schools at Takarazuka (TKRZ), Kawaragi (KWRG), and Suma (SUMA). Kobe site (1180) was chosen to be located on the roof of a building of Kobe University, which is located in the south flank of the Rokko mountain range and is also right in the middle of the hypocentral area. Rokko Farm (1181) site is along the top of Rokko mountain range and is about $5 \mathrm{~km}$ southwest of the highest peak. On Awaji Island, both Tsuna (SANO) and Ichinomiya (ICHI) sites were set at the top of local government buildings. Ichinomiya is located at the southern end of the area of aftershock activity, while Tsuna is located near the eastern coast of the island and is about $7 \mathrm{~km}$ from the aftershock area.

Basically, we used a $24 \mathrm{~h}$ session with $30 \mathrm{~s}$ sampling interval, except at Kobe University (1180) and Rokko Farm (1181) where only $10 \mathrm{~h}$ of tracking was conducted between January 24 to February 3. Table 1 summarizes data sets used in the analyses. Before we established the dial-up system between February 13 to 15 , PC were used to manually or automatically download data. However, due to various troubles such as mis-operation or malfunctioning of PC, data was lost or not recorded at some sites in the initial stage of observation.

After the dial-up system was implemented, data were orderly sent to the data center. We extensively inspected the automatically processed baseline results described below, and this urgent observation system was discontinued at the end of March, except for four sites used for longer monitoring. In this article we use data that was collected through to the end of March.

Two types of analysis were conducted as follows:

1) Absolute ITRF (IERS Terrestrial Reference Frame) coordinate changes for eight sites were estimated assuming Usuda (USUD) site fixed to the instantaneous coordinates derived from ITRF93 and its velocity field (Boucher et al., 1994). Usuda site is one of the IGS (International GPS Service for Geodynamics; see Mueller, 1993) global sites, so its ITRF coordinates are well established. Since it is located about $300 \mathrm{~km}$ northeast of the hypocentral area, no seismic effect was expected. In order to get the highest accuracy in position estimates, we used, first, rapid service of SIO precise orbits that are produced at the Scripps Institution of Oceanography (SIO). Later, IGS final orbits which are collected at the GPS Data and Information Center at ERI were used in obtaining final results. Bernese GPS analyzing software (version 3.5) was used for this purpose. Atmospheric parameters were also estimated together with coordinates. Daily data of $24 \mathrm{~h}$ or data that is longer than $12 \mathrm{~h}$ were used for this analysis.

2) In order to examine deformation of shorter 
Table 1. Data list.

\begin{tabular}{|c|c|c|c|c|c|c|c|c|c|}
\hline Date & DOY & TKRZ & SHKG & KWRG & 1180 & 1181 & SUMA & SANO & ICHI \\
\hline Jan. 18 & 18 & & & & & - & & & \\
\hline Jan. 19 & 19 & & & & - 궁 & - & & & \\
\hline Jan. 20 & 20 & - & - & 0 & - & - & & - & - \\
\hline Jan. 21 & 21 & - & - & 0 & - & - & - & - & - \\
\hline Jan. 22 & 22 & & - & - & - & - & - & 0 & - \\
\hline Jan. 23 & 23 & & $x$ & 0 & - & - & & 0 & - \\
\hline Jan. 24 & 24 & & - & - & 0 & $x$ & & $x$ & - \\
\hline Jan. 25 & 25 & & - & - & 0 & 0 & & - & - \\
\hline Jan. 26 & 26 & & - & - & 0 & 0 & & - & - \\
\hline Jan. 27 & 27 & & - & - & 0 & 0 & & - & - \\
\hline Jan. 28 & 28 & & - & - & 0 & 0 & & - & 0 \\
\hline Jan. 29 & 29 & & - & - & 0 & 0 & & - & \\
\hline Jan. 30 & 30 & & - & - & 0 & 0 & & - & \\
\hline Jan. 31 & 31 & & - & - & 0 & 0 & & $x$ & \\
\hline Feb. 01 & 32 & & - & - & 0 & 0 & & - & \\
\hline Feb. 02 & 33 & & - & - & 0 & 0 & & & 0 \\
\hline Feb. 03 & 34 & & - & - & & & & & - \\
\hline Feb. 04 & 35 & & $x$ & - & & & & - & - \\
\hline Feb. 05 & 36 & & & - & - & & & - & - \\
\hline Feb. 06 & 37 & & 0 & 0 & - & & & - & - \\
\hline Feb. 07 & 38 & & - & - & ㄱ. & & & - & - \\
\hline Feb. 08 & 39 & & - & - & - & & & - & - \\
\hline Feb. 09 & 40 & & - & - & - & & & - & - \\
\hline Feb. 10 & 41 & & - & - & - & & & - & - \\
\hline Feb. 11 & 42 & & - & - & $x$ & & & - & \\
\hline Feb. 12 & 43 & & - & 0 & & & & 0 & 0 \\
\hline Feb. 13 & 44 & 0 & - & - & & & 0 & - & - \\
\hline Feb. 14 & 45 & - & - & - & - & & - & & - \\
\hline Feb. 15 & 46 & - & - & - & - & - & - & - & - \\
\hline Feb. 16 & 47 & - & - & - & - & - & - & - & - \\
\hline Feb. 17 & 48 & - & - & - & - & - & - & - & - \\
\hline Feb. 18 & 49 & - & - & - & - & - & - & - & - \\
\hline Feb. 19 & 50 & - & - & - & - & - & - & - & - \\
\hline Feb. 20 & 51 & 0 & 0 & 0 & 0 & 0 & 0 & 0 & 0 \\
\hline Feb. 21 & 52 & - & - & - & - & - & - & - & - \\
\hline Feb. 22 & 53 & - & - & - & 0 & - & - & 웅 & - \\
\hline Feb. 23 & 54 & - & - & - & - & - & - & - & - \\
\hline Feb. 24 & 55 & - & - & - & - & - & - & - & - \\
\hline Feb. 25 & 56 & - & - & - & - & - & - & - & - \\
\hline Feb. 26 & 57 & 0 & 0 & 0 & - & 0 & 0 & 0 & 0 \\
\hline Feb. 27 & 58 & - & - & - & - & - & - & - & - \\
\hline Feb. 28 & 59 & 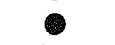 & - & - & - & - & - & - & - \\
\hline Mar. 01 & 60 & - & - & - & - & - & - & - & - \\
\hline Mar. 02 & 61 & - & - & - & - & - & - & - & - \\
\hline Mar. 03 & 62 & 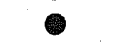 & 둥 & - & - & 둥 & 궁 & 숭 & - \\
\hline Mar. 04 & 63 & - & - & - & - & - & - & - & - \\
\hline Mar. 05 & 64 & - & - & - & - & - & - & - & - \\
\hline Mar. 06 & 65 & 0 & - & - & - & - & 0 & - & - \\
\hline Mar. 07 & 66 & - & - & - & - & - & - & 0 & - \\
\hline Mar. 08 & 67 & - & - & - & - & - & - & - & - \\
\hline Mar. 09 & 68 & - & - & - & - & - & - & - & - \\
\hline
\end{tabular}


Table 1. (continued).

\begin{tabular}{|c|c|c|c|c|c|c|c|c|c|}
\hline Date & DOY & TKRZ & SHKG & KWRG & 1180 & 1181 & SUMA & SANO & $\mathrm{ICHI}$ \\
\hline Mar. 10 & 69 & - & - & - & - & - & - & (-) & 궁 \\
\hline Mar. 11 & 70 & - & - & - & - & - & - & - & - \\
\hline Mar. 12 & 71 & - & 0 & - & - & - & - & - & 궁 \\
\hline Mar. 13 & 72 & - & - & - & - & - & - & - & - \\
\hline Mar. 14 & 73 & - & - & - & - & - & - & - & - \\
\hline Mar. 15 & 74 & - & - & - & - & 궁 & 궁 & - & - \\
\hline Mar. 16 & 75 & - & - & 궁 & - & - & - & - & - \\
\hline Mar. 17 & 76 & - & - & - & - & - & - & - & - \\
\hline Mar. 18 & 77 & - & - & - & - & - & - & - & - \\
\hline Mar. 19 & 78 & - & - & 궁 & - & - & 0 & 궁 & 중 \\
\hline Mar. 20 & 79 & - & - & - & - & - & - & - & - \\
\hline Mar. 21 & 80 & - & - & - & - & - & - & - & - \\
\hline Mar. 22 & 81 & - & - & - & - & - & & & \\
\hline Mar. 23 & 82 & 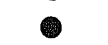 & - & & & & & & \\
\hline Mar. 24 & 83 & - & - & & & & & & \\
\hline Mar. 25 & 84 & - & - & & & & & & \\
\hline Mar. 26 & 85 & - & - & & & & & & \\
\hline Mar. 27 & 86 & - & - & & & & & & \\
\hline Mar. 28 & 87 & - & - & & & & & & \\
\hline Mar. 29 & 88 & - & - & & & & & & \\
\hline Mar. 30 & 89 & - & - & & & & & & \\
\hline Mar. 31 & 90 & - & - & & & & & & \\
\hline
\end{tabular}

- 24-16h; $\mathrm{O}, 16-12 \mathrm{~h} ; \times$, less than $12 \mathrm{~h}$.

time scale and to test rapid dissemination of obtained results, data were truncated into $6 \mathrm{~h}$ sessions, and automatic baseline analysis was conducted. In this case, short baselines were constructed as shown in Fig. 3. On the Kobe side, Shukugawa (SHKG) was taken as the fixed site and the following baselines were constructed; Takarazuka (TKRZ)-Shukugawa (SHKG) $[6.3 \mathrm{~km}]$, Kawaragi (KWRG)-Shukugawa (SHKG) $[3.5 \mathrm{~km}]$, Kobe Univ. (1180)-Shukugawa (SHKG) [9.5 km], Rokko Farm (1181)-Shukugawa (SHKG) [11.2 km], and Suma (SUMA)-Shukugawa (SHKG) $[23.3 \mathrm{~km}]$. On Awaji Island, only the Ichinomiya(ICHI)-Tsuna (SANO) $[8.5 \mathrm{~km}]$ baseline was used for calculation. The WAVE (Weighted Ambiguity Vector Estimator) data analyzing system, which was developed by Trimble Co., Ltd., was used for this purpose. In this analysis, only broadcast orbits were used and atmospheric parameters were not estimated. In order to obtain better accuracy in baseline estimates, Bernese software may have to be used because it allows parameter estimations of atmospheric effects. In the analyses of short baselines, however, the differences in results obtained by different software might be small. Moreover, what we implemented here was the test of rapid dissemination of baseline results and WAVE was the only software installed in the automatic data acquisition and processing system of our laboratory. Thus, we used WAVE software instead of Bernese software for automatic processing.

\section{Results}

Estimated daily geocentric coordinates of eight sites are shown in Fig. 4a-h. Latitude, longitude, ellipsoidal height, and baseline length from Usuda were plotted for each site. In plots of latitudinal change, a MT (magnitude of aftershocks with respect to time) diagram was also plotted. Data for the MT diagram were taken from the internal report of the Kyoto University group (Katao, personal communication).

In order to test the significance of obtained coordinate changes and to estimate their rates, $3 \sigma$ formal errors are shown as error bars, and linear regression analyses were employed for each plot. Error bars are, however, so small that most of them are not visible except in height plots. After the linear regression analyses, yearly change rates together

Vol. 44, No. 4, 1996 

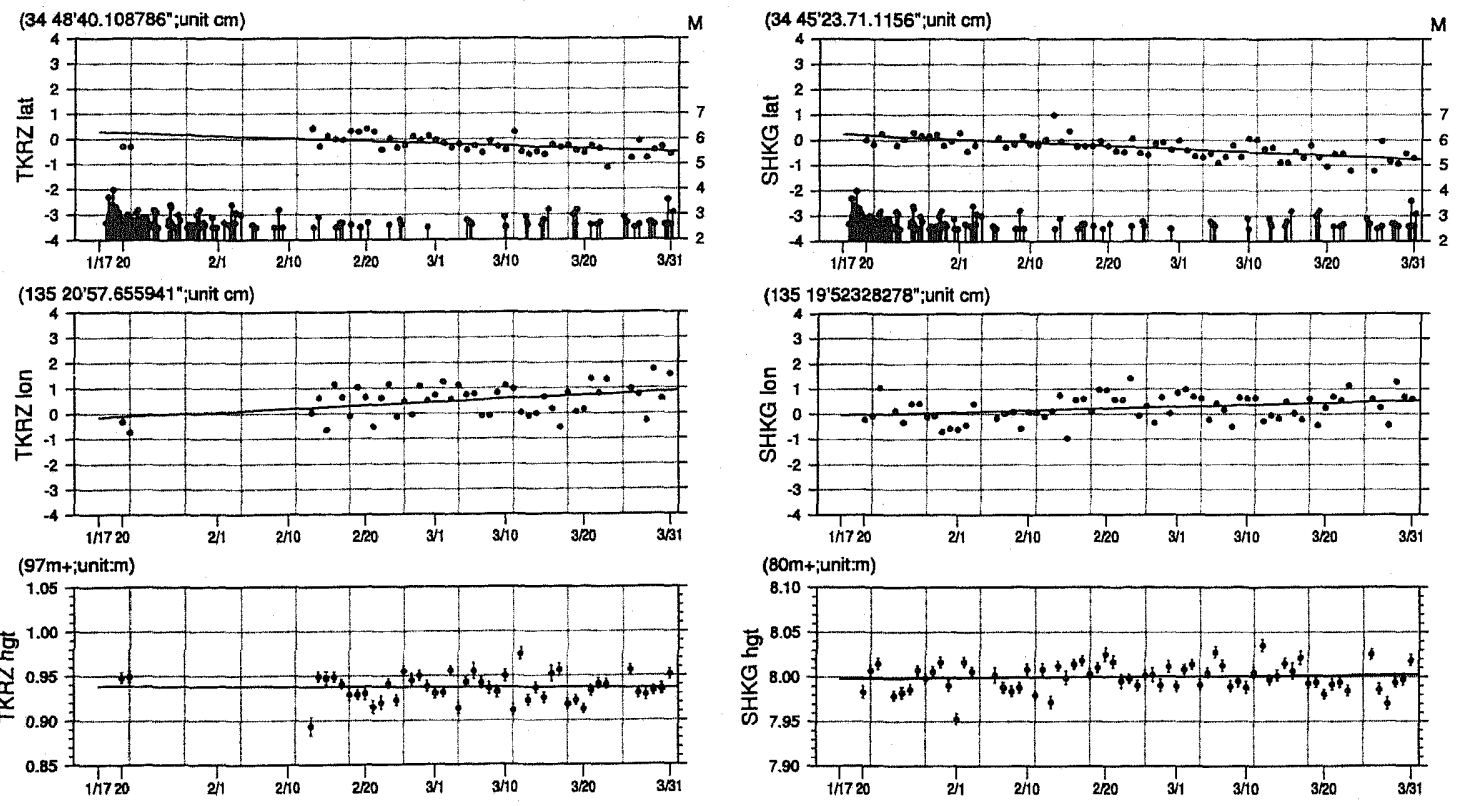

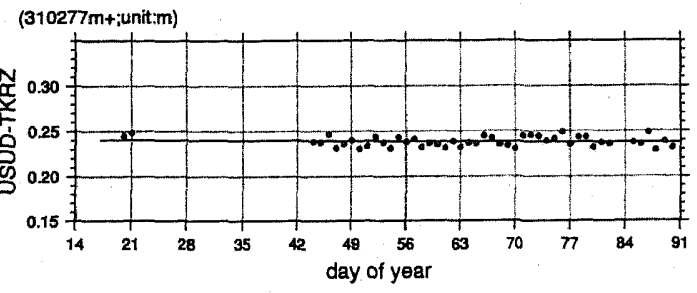

(a)

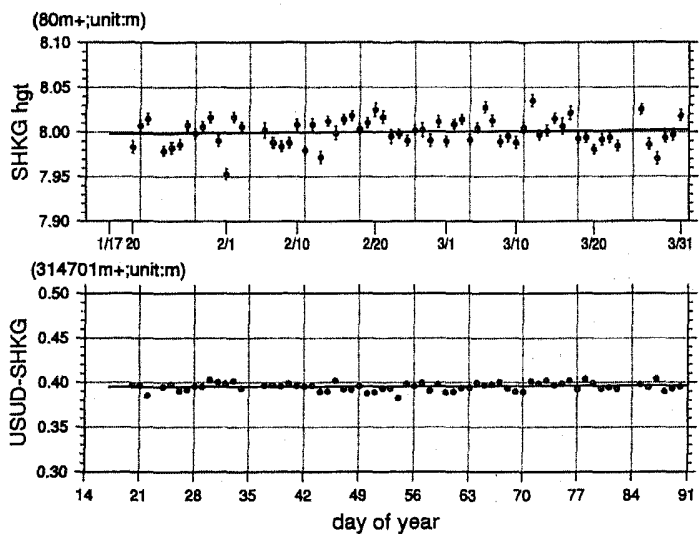

(b)

Fig. 4(a) and (b). Daily coordinate and length changes of (a) Takarazuka (TKRZ), (b) Shukugawa (SHKG). MT diagram is inserted in the latitude plot.

with standard errors at each site were summarized in Table 2. In Table 2, misfits from linear regressions were estimated using the following equation:

$$
\varepsilon=\sqrt{\sum(O-C)^{2} /(N-2)},
$$

where $O$ and $C$ are the observed and calculated values, respectively, and $N$ is the number of data. Results suggest that the daily variability is smallest in the latitude component $(\sim 3 \mathrm{~mm})$, and largest in the height component $(\sim 15 \mathrm{~mm})$.

Figure 5a-f show the results of short baseline analysis. In these figures, differences in latitudes, longitudes, heights, and lengths between sites are displayed.

Brief inspection of these figures reveals that, first, it is readily seen in Fig. 4a-h that all of sites show gradual displacements to the southeast. Among these, large drift to the southeast is seen at Rokko Farm (1181), which amounted to nearly $3 \mathrm{~cm}$ until the end of February (Fig. 4e). The direction of the drift seems orthogonal to the fault strike. Because repeatability of the altitude plot is better than that of longitude, the drift to the south is clear, while the longitudinal drift is less clear. Drift to the southeast at Rokko seems to have ceased at the end of February. Since the site was occupied by a tripod, drift due to artificial or environmental causes may be suspected. However, the site was frequently attended and the vertical plumb line was inspected carefully. In fact, the field observers suggested no significant displacement of the site. Thus, at this moment, the authors are inclining to think that 

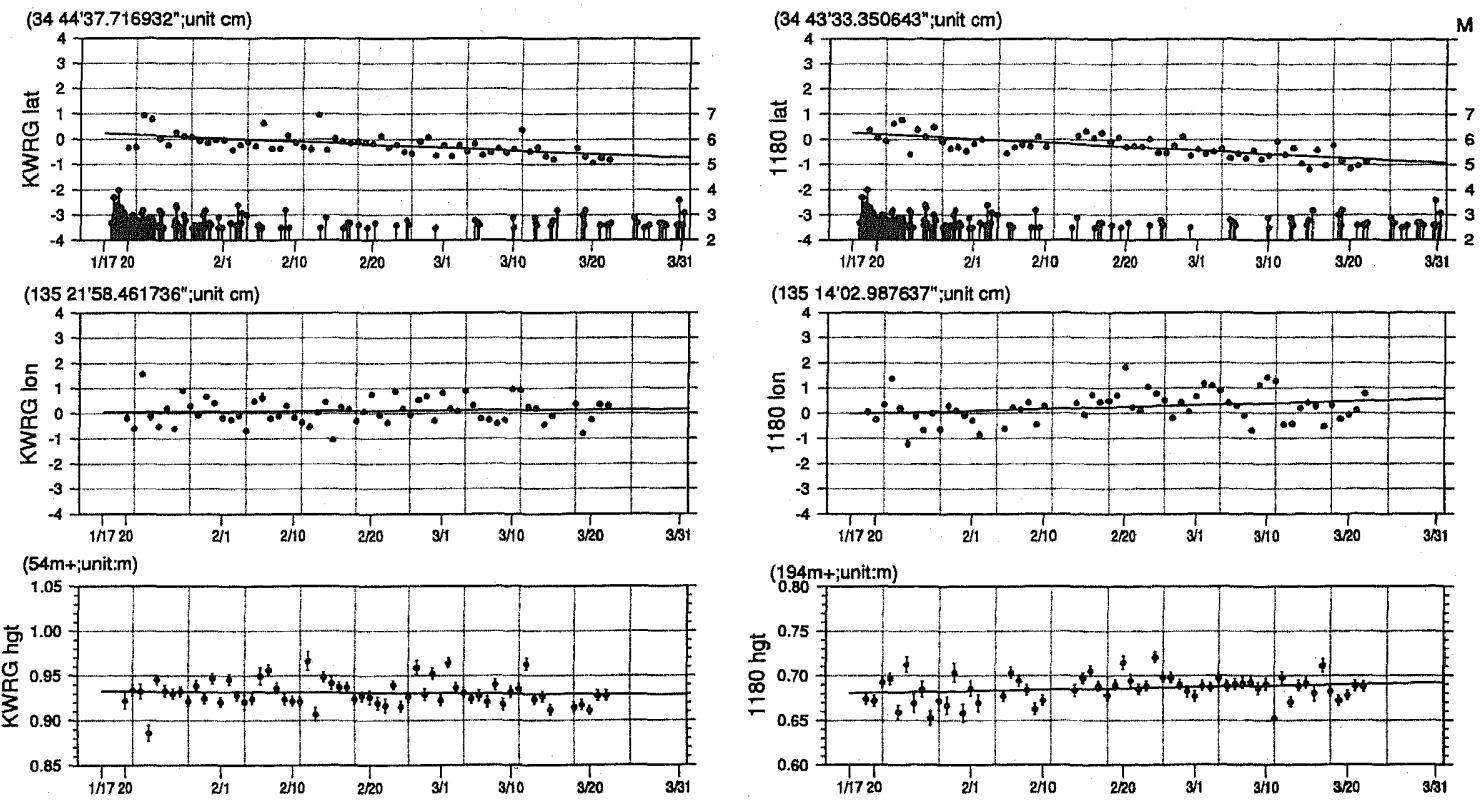

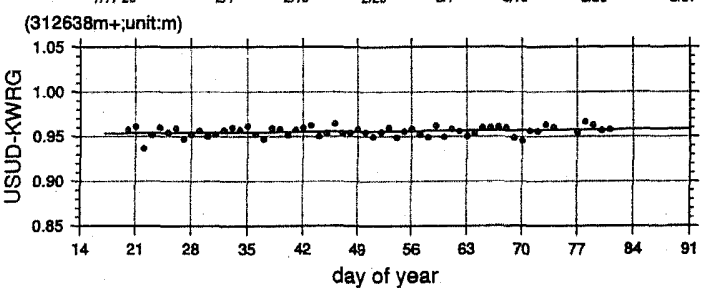

(c)

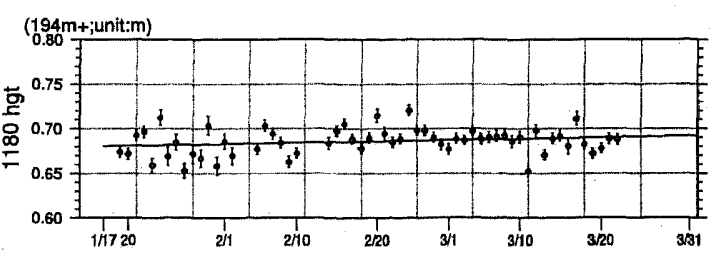

(324103m+;unit:m)

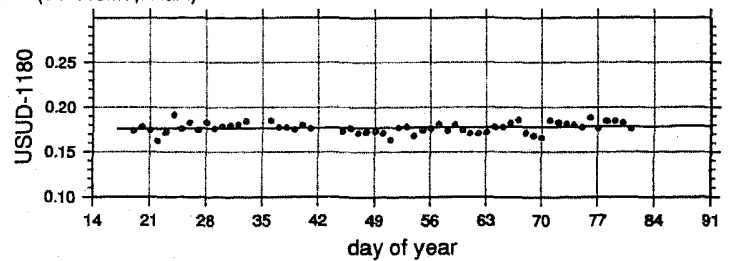

(d)

Fig. 4(c) and (d). Daily coordinate and length changes of (c) Kawaragi (KWRG), (d) Kobe University (1180). MT diagram is inserted in the latitude plot.

the displacement seen at the Rokko site represents crustal deformation at and around the site. Rates of slower drift observed at other sites are roughly $40-90 \mathrm{~mm} /$ year until the end of March (Table 2). The rates are significantly large compared with other aseismic tectonic deformations of the Japanese Islands. Thus, these compartively rapid drifts might also represent a part of the post-seismic readjustment of stress in the crust. However, since these drifts might be contaminated by seasonal change, it would be premature to conclude that they are real post-seismic deformations.

It may be of special interest if acute post-seismic displacement is seen right after the earthquake. Such acute drift, although small, may be seen at the sites on the Awaji Island (ICHI and SANO), and seems to have continued until January 22 or 23 (Fig. $4 \mathrm{~g}$ and $\mathrm{h}$ ). After this imminent post-seismic deformation, displacements seems to have turned to the opposite direction and again turned back at around day 35 (beginning of February). At around day 42 (February 11), sites seems to show turn-around again, and, later on, southeastward drift may be seen. However, their amplitudes are too small to conclude that these short term changes are in fact real crustal deformation.

Closer inspection of short baselines in Fig. 5 might reveal local straining around the hypocentral area. TKRZ-SHKG, for example, shows steady extension of baseline length and the opposite is true in KWRG-SHKG. ICHI-SANO baseline also shows contraction. Again, it should be pointed out

Vol. 44, No. 4, 1996 

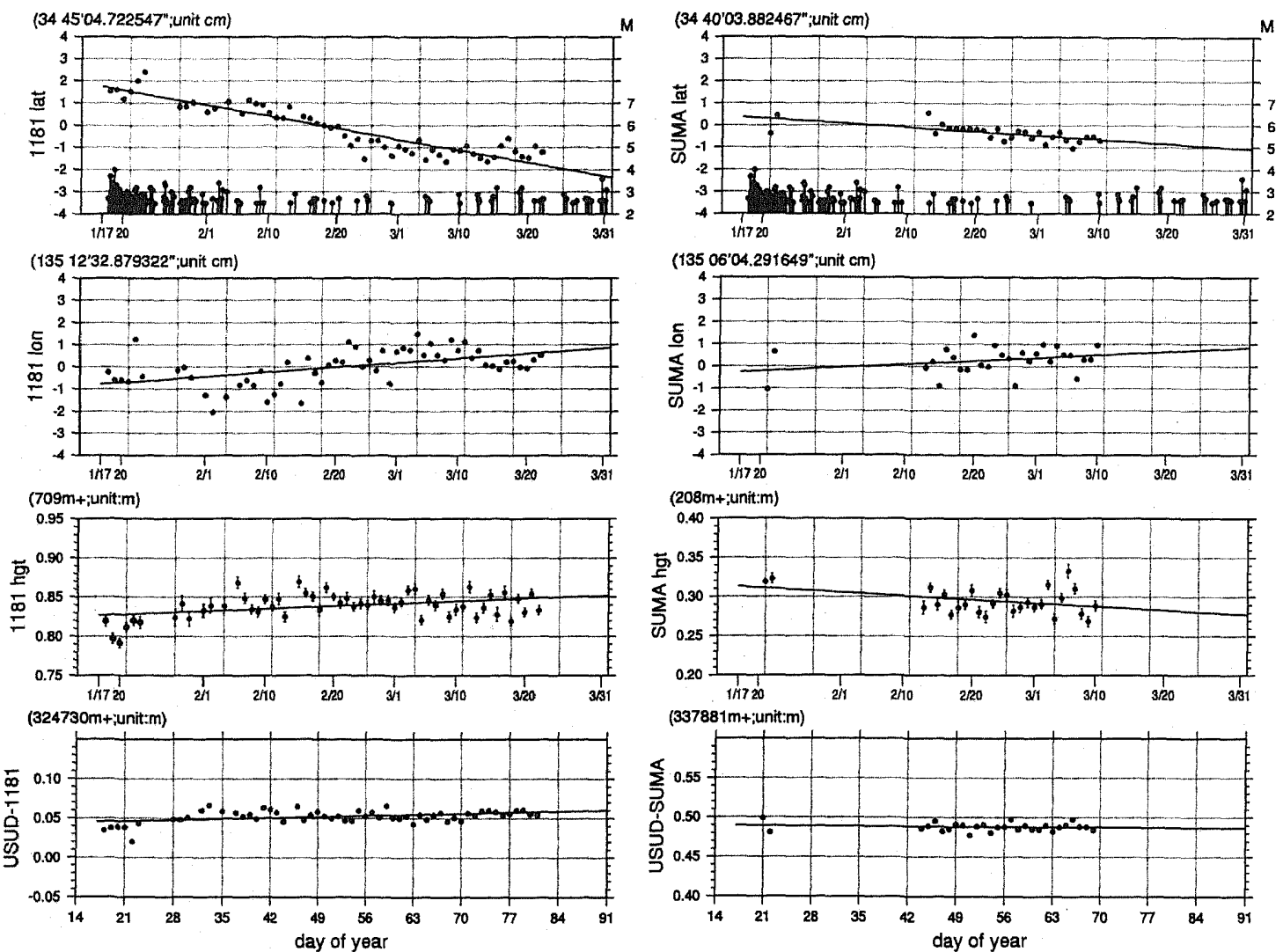

(e)

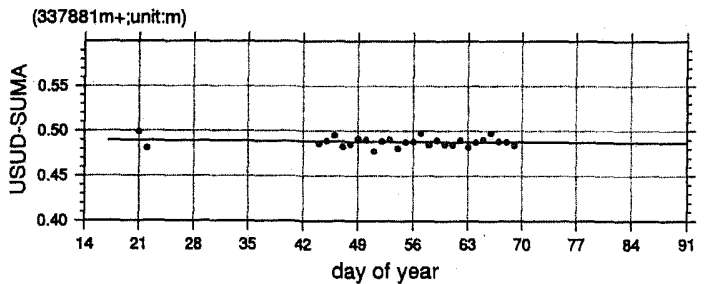

(f)

Fig. 4(e) and (f). Daily coordinate and length changes of (e) Rokko Farm (1181), (f) Suma High School (SUMA). MT diagram is inserted in the latitude plot.

that these slow drifts may be contaminated by other non-tectonic causes such as seasonal changes.

Inset MT diagrams represent areal post-seismic activity. For sites in the Kobe area (Fig.4a-f) MT diagrams were made using earthquakes with epicenters north of latitude $34^{\circ} 37^{\prime} \mathrm{N}$, while these in the Awaji area (Fig. 4g and h) were made using earthquakes south of $34^{\circ} 37^{\prime} \mathrm{N}$. These insets might also show that the turn-around of post-seismic crustal deformation is somehow related to the change in seismic activities, though the relationship is not very clear.

\section{Discussion}

Post-seismic surface deformations have commonly been observed for large earthquakes such as the
1896 Riku-u earthquake (Thatcher et al., 1980), the 1946 Nankai earthquake (e.g. Thatcher and Rundle, 1979; Savage and Thatcher, 1994), the 1964 Alaska earthquake (e.g. Savage and Plafker, 1991), the 1974 Izu-hanto-Oki earthquake (Geological Survey of Japan, 1981), the 1974 Nemuro-Oki earthquake (Kasahara and Kato, 1980), etc. These examples have provided us with useful information in revealing long-term build up of stress in and around the fault as well as the viscoelastic behavior of the crust and the upper mantle. Recent cases were reviewed by Hudnut (1995).

Generally speaking, post-seismic effects have been categorized into two parts; imminent deformation that continues for 2 to 3 years, and longer term gradual deformation that continues for several tens 

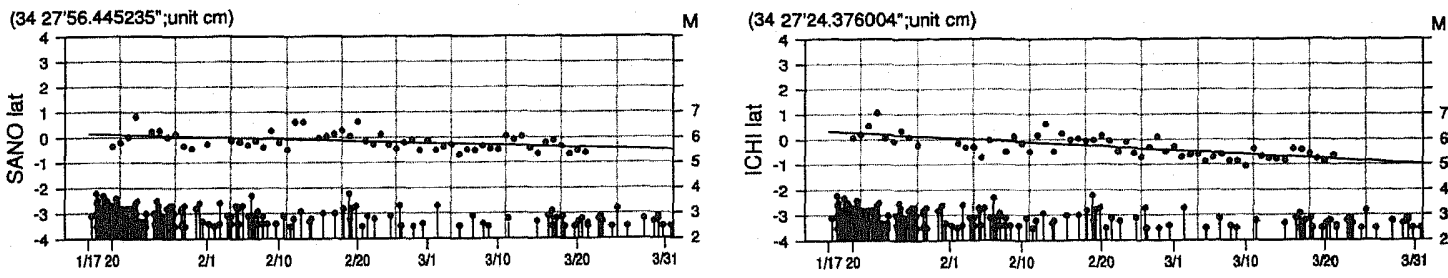

(134 56'24.488333"; unit cm)

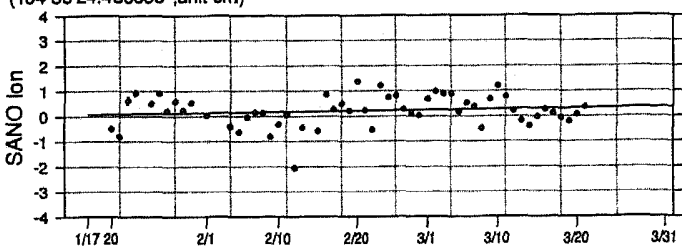

(13450'53.146109"; unit cm)
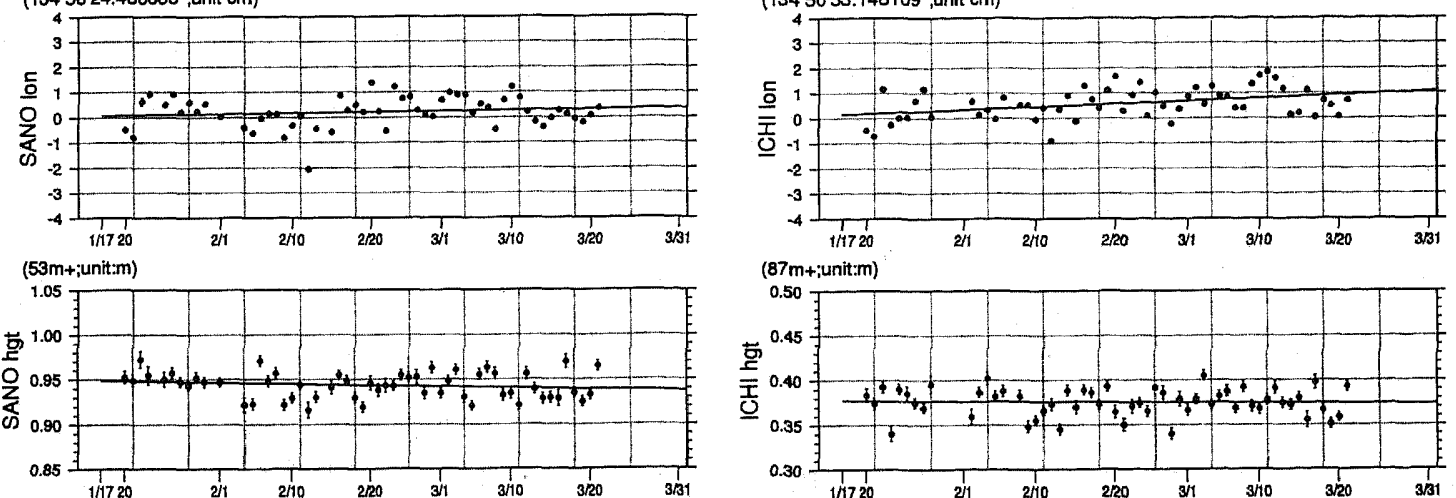

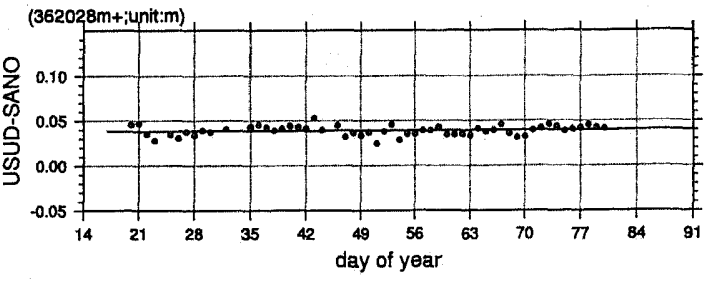

(g)

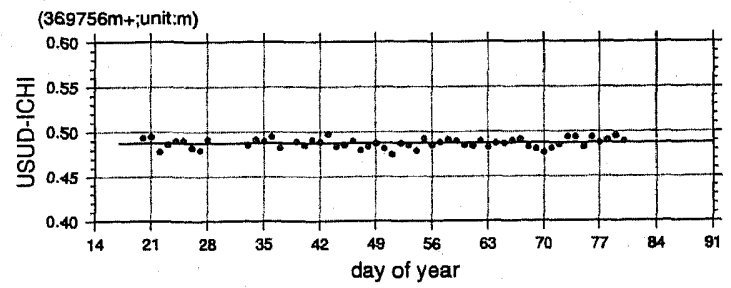

(h)

Fig. 4. Daily coordinate and length changes of (g) Tsuna (SANO), and (h) Ichinomiya (ICHI) relative to Usuda. MT diagram is inserted in the latitude plot.

Table 2. Yearly rates of site displacements after the Hyogo-ken Nanbu earthquake.

(unit: $\mathrm{mm} /$ year)

\begin{tabular}{|c|c|c|c|c|c|}
\hline \multirow{2}{*}{ Site } & \multicolumn{3}{|c|}{ Component wise expression } & \multicolumn{2}{|c|}{ Vector expression } \\
\hline & N-S component & E-W component & U-D component & Amplitude & Deg. from $N$ to $E$ \\
\hline Takarazuka (TKRZ) & $-36.5 \pm 9.5(2.9)$ & $51.0 \pm 19.3(5.8)$ & $-9.9 \pm 51.4(15.5)$ & 62.7 & 125.6 \\
\hline Shukugawa (SHKG) & $-49.6 \pm 6.9(3.1)$ & $28.6 \pm 11.4(5.1)$ & $24.1 \pm 34.2(15.2)$ & 57.3 & 150.0 \\
\hline Kawaragi (KWRG) & $-46.5 \pm 8.7(3.3)$ & $52.9 \pm 13.8(5.2)$ & $-18.3 \pm 39.9(14.9)$ & 70.4 & 131.3 \\
\hline Kobe Univ. (1180) & $-59.4 \pm 8.2(3.2)$ & $28.8 \pm 15.5(6.0)$ & $56.2 \pm 37.0(14.4)$ & 66.0 & 154.1 \\
\hline Rokko (1181) & $-201.5 \pm 11.7(4.3)$ & $80.6 \pm 18.6(6.9)$ & $125.9 \pm 40.0(14.9)$ & 217.0 & 158.2 \\
\hline Suma (SUMA) & $-71.8 \pm 16.6(2.8)$ & $54.8 \pm 34.5(5.8)$ & $-174.8 \pm 91.9(15.4)$ & 90.3 & 142.6 \\
\hline Tsuna (SANO) & $-31.8 \pm 8.6(3.1)$ & $14.9 \pm 17.1(6.1)$ & $-54.0 \pm 39.9(14.3)$ & 35.1 & 154.9 \\
\hline Ichinomiya (ICHI) & $-64.6 \pm 8.6(3.1)$ & $45.9 \pm 16.1(5.8)$ & $-16.8 \pm 43.7(15.6)$ & 79.2 & 144.6 \\
\hline
\end{tabular}

Values in parentheses are the rms of regression obtained by $\sqrt{\sum(O-C)^{2} /(N-2)}$.

Vol. 44, No. 4, 1996 
Takarazuka - Shukugawa
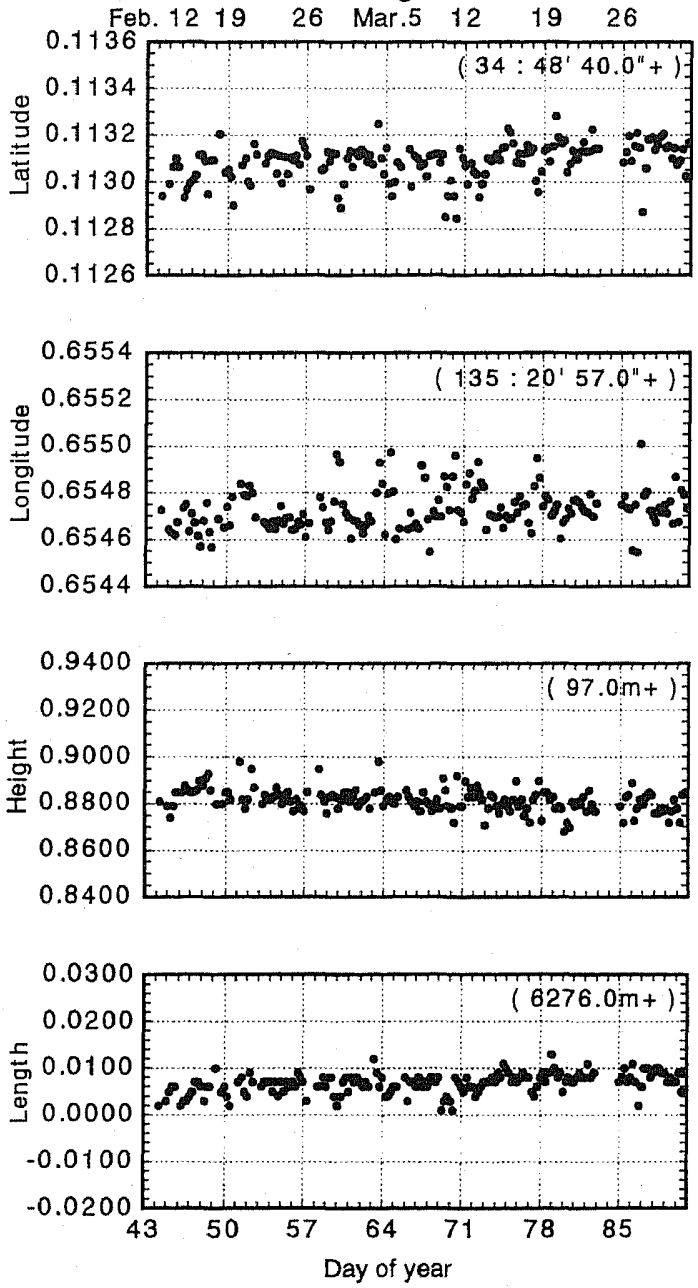

(a)
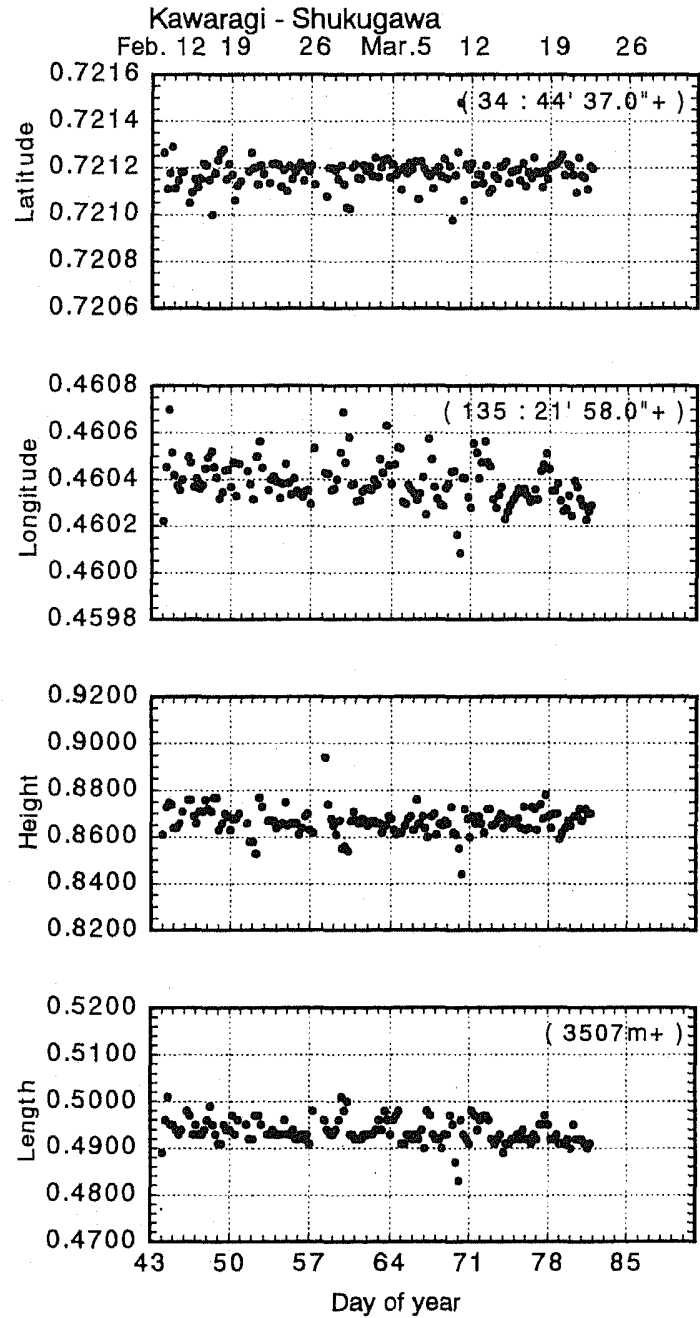

(b)

Fig. 5(a) and (b). Baseline and length changes of (a) TKRZ-SHKG, (b) KWRG-SHKG by 6-h session data.

of years or longer. The first imminent deformations have been modelled by a downward extension of the faultings (e.g. Thatcher and Rundle, 1979; Kasahara and Kato, 1981). Retarded slip on the fault segment might be also plausible (Geological Survey of Japan, 1981). Longer term deformations of exponential decay have also been used for estimating the viscoelastic property of the crust and the upper mantle (Thatcher et al., 1980; Thatcher and Rundle, 1979).

The 1995 Hyogo-ken Nanbu earthquake may provide us with a good example to examine the mechanisms of post-seismic deformation. Although it seems too early to conclude, results from the first 2 months of GPS data suggest that significant areal deformations that cover the whole area of the hypocentral region seem to be taking place. Local deformation has also been found in the area of Rokko Mountain (see also Hirahara et al., 1996) and local strainings seem also to be taking place.

Towards the end of this urgent project, the Geographical Survey Institute began to establish permanent sites in the same region. The University group also left four permanent sites around the 
Kobe Univ. - Shukugawa
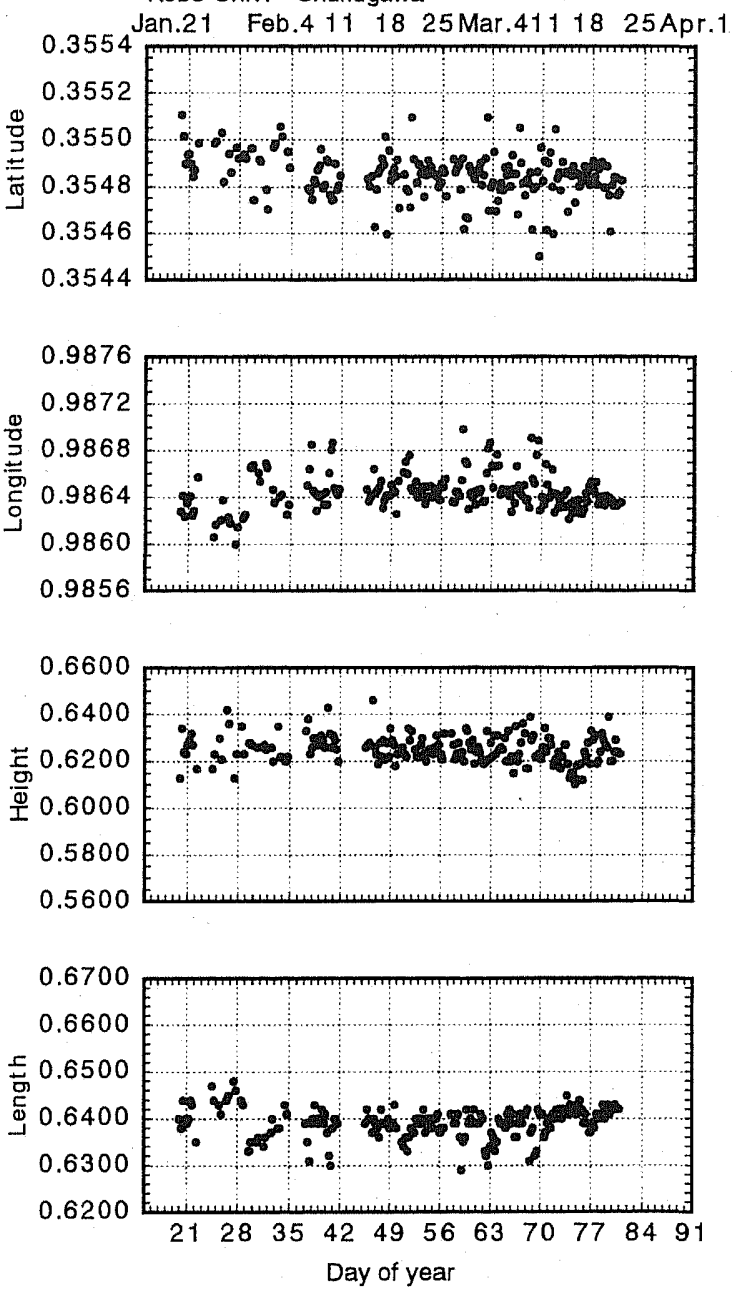

(c)
Rokko Farm - Shukugawa

Jan.21 Feb.411 18 25Mar.411 18 25Apr.1
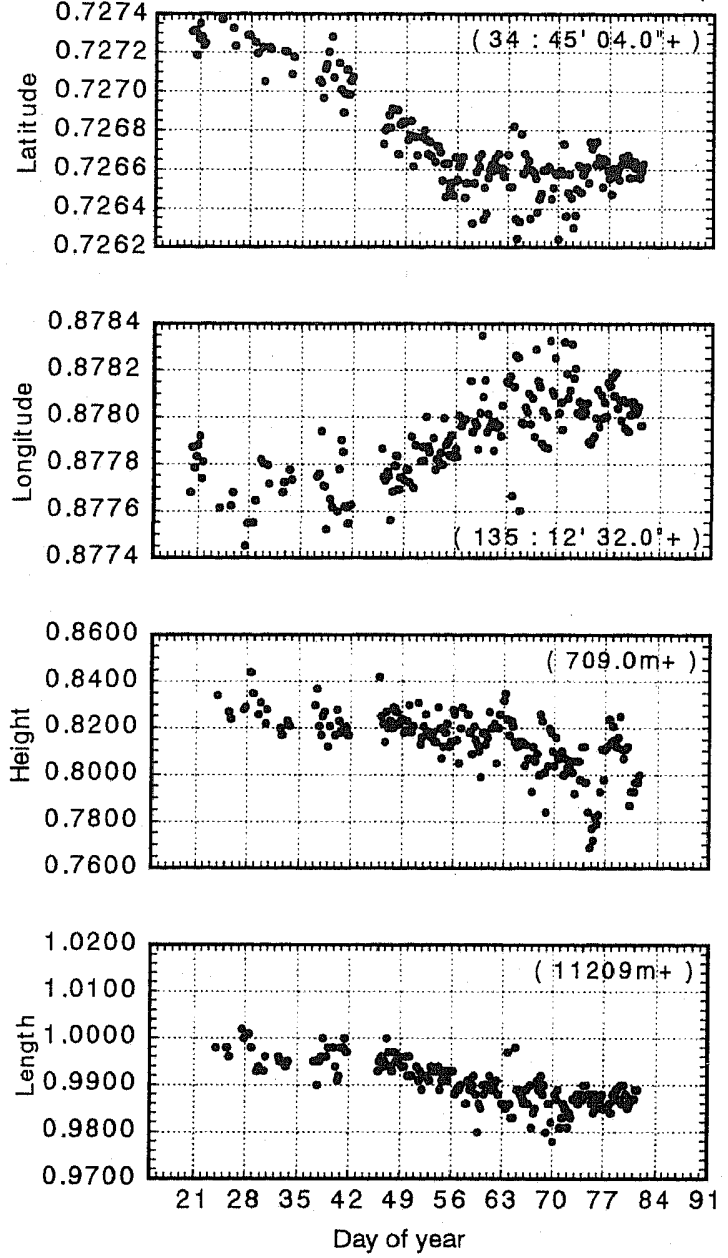

(d)

Fig. 5(c) and (d). Baseline and length changes of (c) 1180-SHKG, (d) 1181-SHKG by 6-h session data.

hypocentral area. Their detailed observations using dense GPS arrays will reveal longer-term displacements and their mechanisms to an extent that no other research has ever reached.

Deformation seen at the Rokko site (1181) is another point of interest. Judging from Figs. 4d, e and $5 \mathrm{c}, \mathrm{d}$, it seems that the deformation took place toward the southeast, which is normal for the fault strike. This displacement continued until the end of February when it gradually ceased. There could be a some possible mechanisms to interpret it;

1) Local viscoelastic response due to sudden burden of the elastic deformation of the crust and the upper mantle occurred. However, the time-scale of 1 month and half might be too short.

2) The gravitational landslide of Rokko mountain which was triggered by the landslide associated with the main shock and successive aftershock activity. However, landslide data by the Geographical Survey Institute (1995) shows that the landslide area is too small and far-away to account for the amplitude of the deformation.

3) Afterslip occurred on the fault surface and considering that the inverted displacements by Yoshida

Vol. 44, No. 4, 1996 

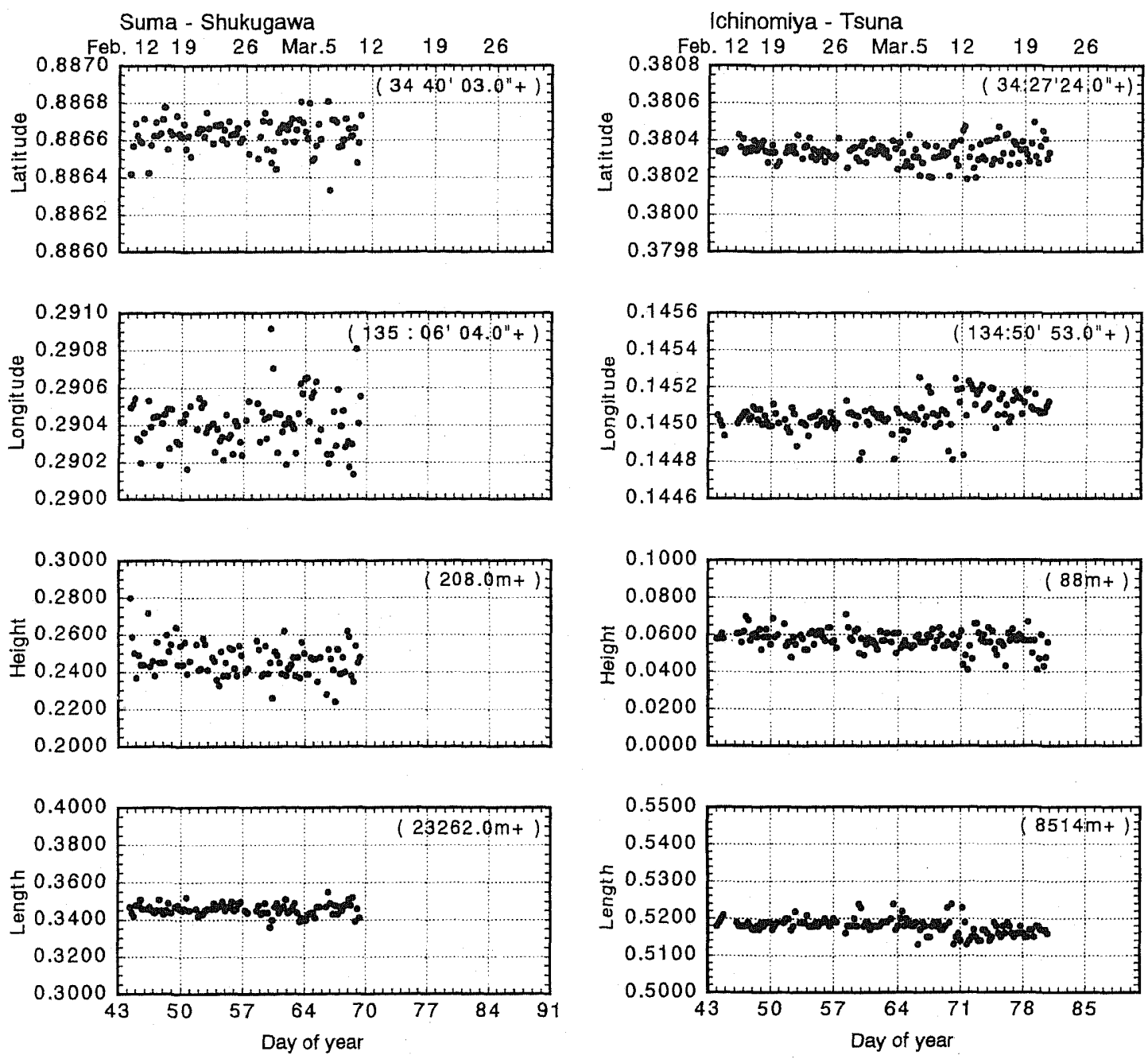

(e)

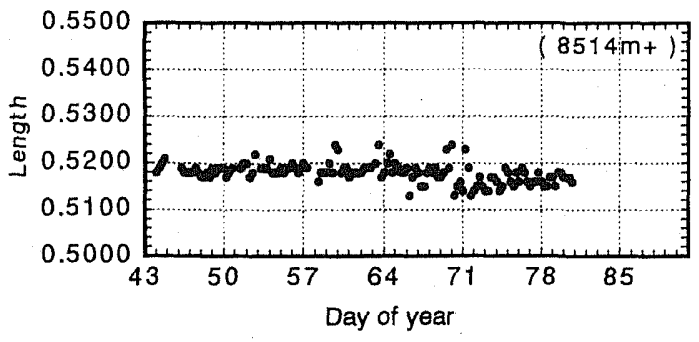

(f)

Fig. 5. Baseline and length changes of (e) SUMA-SHKG, (f) ICHI-SANO by 6-h session data.

et al. (1996) indicate that the fault is dipping towards the south, so that if vertical component of displacement continued on the fault surface, displacement normal to the fault might be observed.

It seems, however, premature to determine the exact mechanism for the post-seismic drift seen at Rokko and other parts of the studied area. Integration of various types of geophysical data such as strain and tilt measurements, together with longerterm observations, may have to be incorporated for this purpose (Hudnut, 1995).

\section{Conclusion}

The Japanese University GPS Consortium for GPS Research constructed a dense array of more than 30 GPS sites around the hypocentral area of the Hyogo-ken Nanbu earthquake of January 17, 1995. Data analysis from the eight selected sites that were positioned close to the hypocentral area showed significant post-seismic crustal deformation.

First, the gradual drift of coordinates was seen at all of the analyzed sites. Of these sites, Rokko Farm, which is located north of the fault, showed rapid 
post-seismic crustal deformation until the end of February. Results revealed displacements of about $3 \mathrm{~cm}$ toward the southeast, which is nearly normal of the fault strike. Although there could be some possible mechanisms for interpreting the crustal deformation, such as viscoelastic recovery, gravitational landslide due to the earthquake, post-seismic vertical offset on the fault surface, it seems premature to pinpoint the exact mechanism.

Second, although acute and successive undulatory displacements could be seen at sites on Awaji Island, their amplitudes seem too small to be judged as real crustal deformation.

Third, short baseline analyses showed that local areal strainings seem to be taking place both at Kobe and Awaji areas, although longer observations are needed to investigate the seasonal effects.

Longer-term observations with dense GPS arrays in and around the focal region, chiefly maintained by the Geographical Survey Institute and University group, will provide us with invaluable data to reveal the physical mechanisms of post-seismic deformation in the crust and the upper mantle.

This study could not have materialized without the assistance rendered by many local people, from school administrators to other officials and ordinary citizens; we wish to express our deepest gratitude for this help. It is especially worth noting that we received support from many that were facing great calamity themselves, people who experienced most trying times amidst the devastation; to them we would like to offer our sincerest condolences, share in their sorrow, and thank them once again for the support they gave in helping us to establish our sites. Dr. Kiyoshi Takano of the Earthquake Research Institute, the University of Tokyo, provided us with Internet facilities to exchange information and disseminate data while Dr. Hiroshi Katao of the Disaster Prevention Research Institute, Kyoto University, provided us with hypocenter data. We would like to express our gratitude to them. We also thank Dr. Ken Hudnut of the U. S. Geological Survey, who gave us invaluable comments on post-seismic deformations, and Dr. Sungat Altis of the Earthquake Research Institute, who critically reviewed the manuscript, as well as Sumiko Ogino and Kazuko Noguchi who helped in the present project. This research was supported by the Ministry of Education, Science, Sports and Culture under the program of Grant-in-Aid for Co-operative Research (A) (No. 06306022) and the program of the Urgent Joint Observation of the 1995 Hyogo-ken Nanbu Earthquake.

\section{REFERENCES}

Boucher, C., Z. Altamimi, and L. Duhem, Results and analysis of the ITRF93, IERS Tech. Note, 18, 313, 1994.

Geographical Survey Institute, Heisei 7-nen Hyogo-ken Nanbu Jishin Saigai Genkyo-zu (Ver. 2), GSI Tech. Rep., D1-No.322, 1995 (in Japanese).

Geological Survey of Japan, After-seismic movement of the Irozaki earthquake fault, Rep. Earthq. Coord. Comm. Earthq. Predict., 24, 1980 (in Japanese).

Gurtner, W. and G. Mader, Receiver independent exchange format Version 2, GPS Bull., 3, 1-8, 1990.

Hashimoto, M., T. Sagiya, H. Tsuji, Y. Hatanaka, and T. Tada, Co-seismic displacements of the 1995 Hyogo-ken Nanbu earthquake, J. Phys. Earth, 44, 255-279, 1996.

Hirahara, K., T. Nakano, M. Kasahara, H. Takahashi, R. Ichikawa, S. Miura, T. Kato, S. Nakao, Y. Hirata, Y. Kotake, T. Chachin, F. Kimata, K. Yamaoka, T. Okuda, H. Kumagai, K. Nakamura, K. Fujimori, T. Yamamoto, T. Terashima, J. P. Catane, K. Tadokoro, A. Kubo, S. Otsuka, A. Tokuyama, T. Tabei, T. Iwabuchi, and T. Matsushima, GPS observations of post-seismic crustal movements in the focal region of the 1995 Hyogo-ken Nanbu earthquake - Static and real-time kinematic GPS observations, J. Phys. Earth, 44, 301-315, 1996.

Hudnut, K., Earthquake geodesy and hazard monitoring, Rev. Geophys., 33, Suppl., 249-255, 1995.

Kasahara, K., and T. Kato, 1980, Aseismic faulting following the 1973 Nemuro-oki earthquake, Hokkaido, Japan (a retrospective study). Pure Appl. Geophys., 119, 392-403.

Mueller, I., The International GPS service for geodynamics: An introduction, Proc. 1993 IGS Workshop (ed. G. Beutler and E. Brockman), 1-3, 1993.

Research Group for Active Faults of Japan, Active Faults in Japan-Sheet Maps and Inventories, University of Tokyo Press, Tokyo, 1991.

Savage, J. and G. Plafker, Tide measurements of uplift along the south coast of Alaska, J. Geophys. Res., 96, 4325-4335, 1991.

Thatcher, W. and J. B. Rundle, A model for the earthquake cycle in underthrust zones, J. Geophys. Res., 84, 5540-5556, 1979.

Thatcher, W., T. Matsuda, T. Kato, and J. B. Rundle, Lithospheric loading by the 1896 Riku-u earthquake, northern Japan: Implications for plate flexure and asthenospheric rheology, J. Geophys. Res., 85, 64296435, 1980.

Yoshida, S., K. Koketsu, B. Shibazaki, T. Sagiya, T. Kato, and Y. Yoshida, Joint inversion of near- and far-field waveforms and geodetic data for the rupture process of the 1995 Kobe earthquake, J. Phys. Earth, 44, 437-454, 1996. 